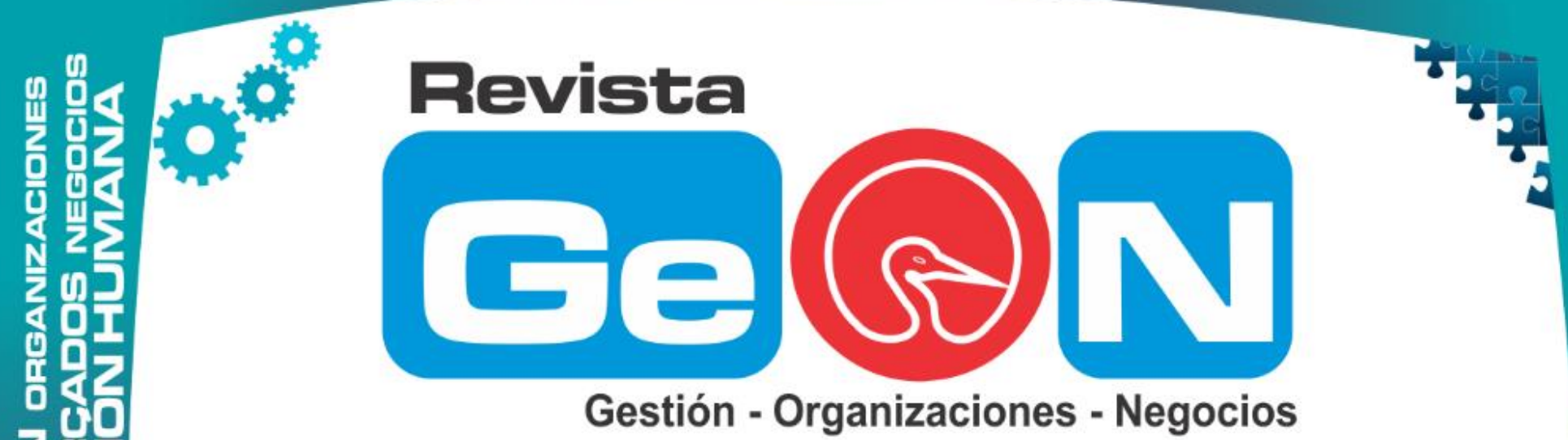

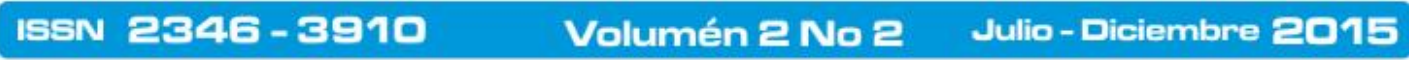

Revista Electrónica de la Facultad de Ciencias Económicas de la Universidad de los Llanos

1. 3 II

440

VILLAVICENCIO - COLOMBIA

$>2$

64

2

2 平品

70

ব)

展

o

ii III

0 U

ใด

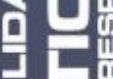

居的

임

Iiin in

照

只

造

iil 2

if in

4 吕

2

400

付 iI
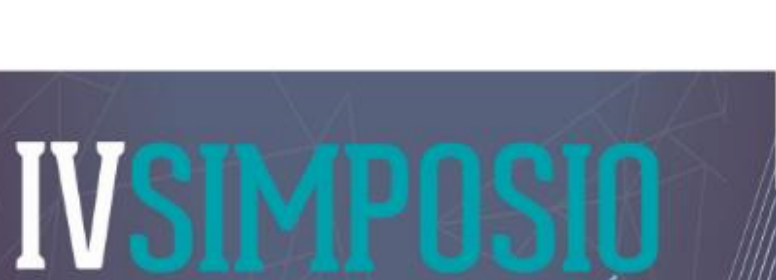

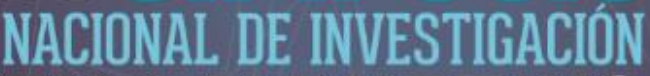

EN MARKETING
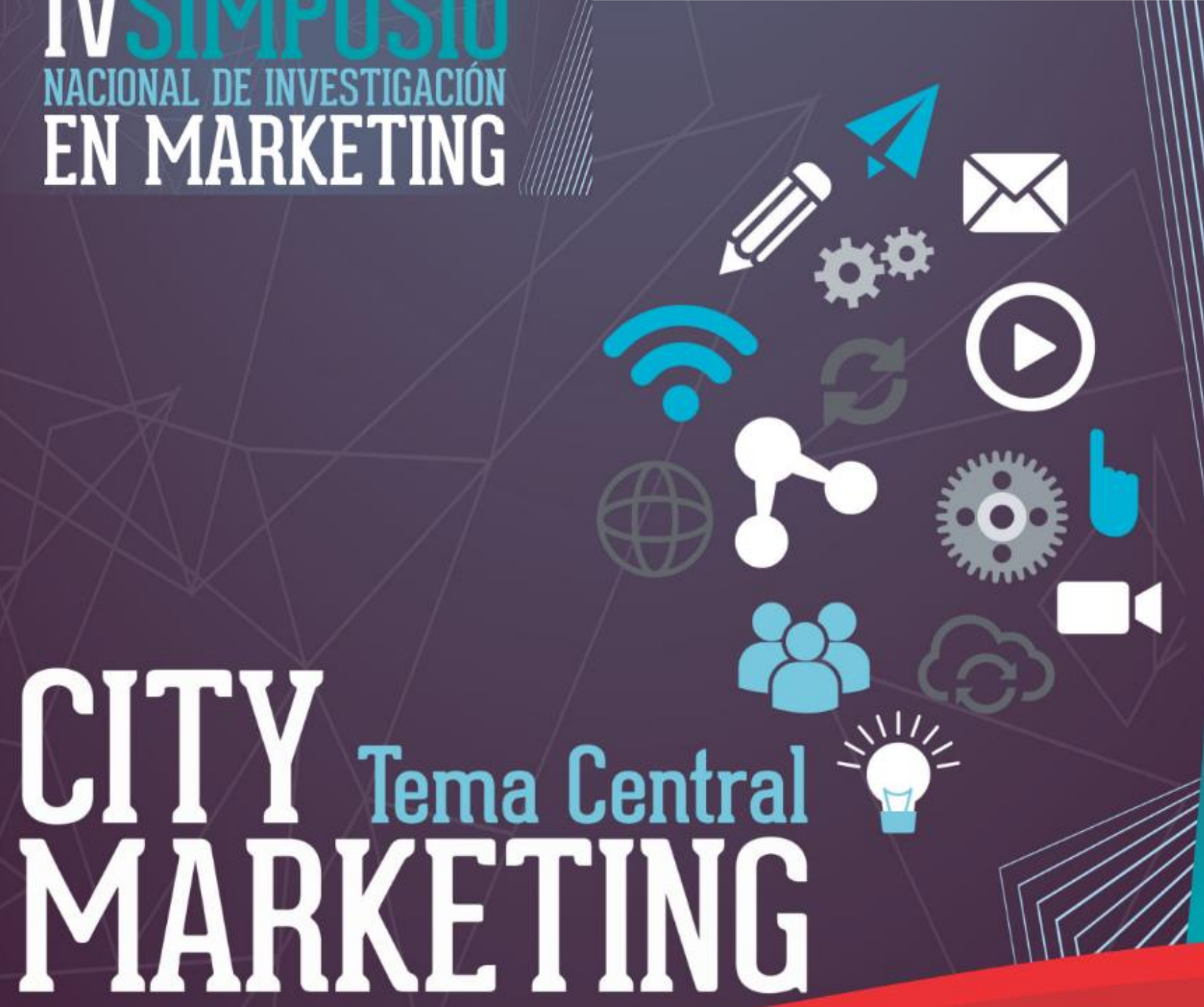

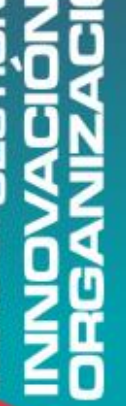
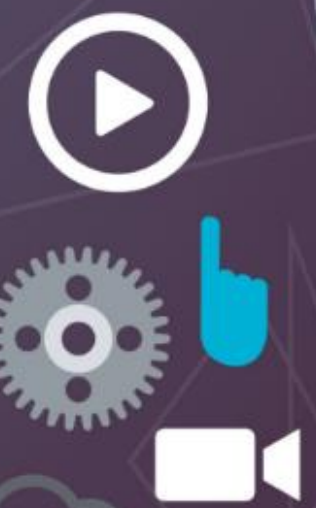


\section{Estudio de mercado nuevo producto: desinfectante natural - Natalia Castaño - María Huertas - Madeline Melchor}

\author{
Natalia Castaño de la Cruz \\ Estudiante de Mercadeo y Negocios \\ Internacionales Universidad Autónoma de \\ Occidente. \\ nataliac789@hotmail.com
}

María Camila Huertas Umaña

Estudiante de Mercadeo y Negocios Internacionales Universidad Autónoma de Occidente.

h.macamila@hotmail.com

@Kmihu

Madeline Melchor Cardona

Magister en Ingeniería.

mmelchor@uao.edu.co

\section{Resumen}

La desinfección del agua y de los alimentos como frutas y verduras ha sido un factor muy importante para el cuidado de la salud, debido a las enfermedades transmitidas por los alimentos (ETAS) y las enfermedades de origen hídrico. La presente investigación identificó los métodos de desinfección utilizados para el agua, frutas y verduras entre las amas de casa, así como conocer el nivel de aceptación y la percepción que tiene el segmento de estudio frente al lanzamiento de un nuevo producto desinfectante natural que elimina el $99,99 \%$ de las bacterias y microorganismos patógenos. Se encontró que no es un hábito el uso de productos desinfectantes para el agua, frutas y verduras, sin embargo si se manifestó alto interés en la intención de compra del nuevo producto objeto de estudio.

\section{Palabras Clave}

Intención de compra; Métodos de desinfección; Desinfectante Natural

\begin{abstract}
Disinfection of water and food like fruits and vegetables has been a very important health care factor due to foodborne (ETAS) and water-borne diseases transmitted diseases. This research identified the methods used for water disinfection, fruit and vegetables between housewives and knows the level of acceptance and perception of the study segment against a new natural disinfectant that eliminates 99, $99 \%$ of bacteria and pathogens. It was found that is not a habit to use disinfectant for water, fruits and vegetables, however if high interest in the intention of purchasing the study product.
\end{abstract}

\section{Keywords}

Purchase intent, disinfection methods, natural disinfectant.

\section{Introducción}

La desinfección del agua y de alimentos (frutas, verduras) es una forma de prevenir las enfermedades de origen hídrico y las transmitidas por alimentos, por lo que se hace necesario darle la importancia que se merece, ya que está en juego la salud de las personas. Es importante que se realicen estos procedimientos de desinfección a fin de reducir la problemática de salud pública que gira alrededor de estos factores de riesgo como son el de consumir agua de dudosa procedencia y alimentos contaminados. En los últimos 50 años, la elevada presencia y diversidad de manifestaciones clínicas representan un problema relevante dentro de la salud pública, especialmente en los países en vías de desarrollo (Devera et al, 2006). Hoy en día las personas no cuentan con una verdadera cultura de desinfección, ya que primero los hábitos de desinfección que se realizan en los hogares no son totalmente eficientes y seguros, y segundo por el desconocimiento real del tema, en donde, por 
ejemplo, hay hogares que manejan mitos como de utilizar el agua del acueducto para desinfectar los alimentos y otros que ni siquiera, por desconocimiento, solo se limitan a enjuagarlos, con el riesgo que esto implica para la salud.

\section{Enfermedades Transmitidas por Los Alimentos (ETA)}

De lo anterior se puede decir que una de las principales causas de enfermedades gastrointestinales en el mundo, son generadas por el consumo de agua mal tratada y de alimentos que no cuentan con una adecuada desinfección. Las enfermedades transmitidas por alimentos (ETA) constituyen uno de los problemas de salud más extendidos en el mundo contemporáneo y son un factor de gran importancia en la reducción de la productividad económica (Rayner y Scarborough, 2005). En lo referente a este tipo de enfermedades, el Instituto Nacional de Salud (2012) señala que las enfermedades transmitidas por alimentos (ETA), se originan por consumir alimentos o bebidas contaminadas. Se han descrito más de 250 enfermedades diferentes transmitidas por los alimentos, en su mayoría enfermedades e infecciones, ocasionadas por distintas bacterias, virus y parásitos que pueden ser transmitidos por los alimentos. La gran mayoría de los parásitos intestinales se transmiten por contaminación del ambiente, por lo cual el agua y los alimentos juegan un papel importante (Solarte, Peña y Madera, 2006).

\section{Contexto en Colombia}

De acuerdo con el panorama de las ETAS en Colombia cabe resaltar que según Castro \& Mosquera (2013) las actividades realizadas en los hogares en lo relacionado con la manipulación de los alimentos tienen una gran incidencia en los eventos relacionados con las estadísticas de las Enfermedades Transmitidas por los Alimentos los cuales representan el 50\% (366 brotes), seguido de los diferentes restaurantes comerciales con un $15 \%$ (113 brotes) y establecimientos educativos $10 \%$ (78 brotes). Teniendo como base los informes presentados por el ministerio de salud.

Dentro de los diferentes factores de riesgo identificados cabe resaltar que se encuentra: inadecuada conservación de alimentos (177 brotes), inadecuado almacenamiento de alimentos (135 brotes), fallas en cadena de frío (111 brotes), y por último pero no menos importante se encuentra la inadecuada manipulación de alimentos en donde se visibiliza más el hecho de no desinfectar adecuadamente los alimentos que no son sometidos a un proceso de cocción (crudos) y así mismo todo lo relacionado con la limpieza y desinfección del área donde se elaboran y consumen los alimentos.

Además de la desinfección de los alimentos, también es importante tener en cuenta que tipo de agua estamos consumiendo, especialmente la que se utiliza para beber y hacer jugos, porque según su procedencia se debe tener la precaución de contar con un adecuado sistema de desinfección para con el agua.

En el contexto colombiano cabe resaltar que según el Departamento Administrativo de Estadística (DANE, 2008), el 25,8\% de hogares en Colombia tenía problemas con el agua que utilizaban para preparar sus alimentos, de lo cual Vidal (2010) sostiene al decir que muchos de estos hogares Colombianos hoy por hoy no reciben un suministro de agua tratada, lo cual los lleva a tener que tomarla de los diferentes nacimientos, ríos, de aguas lluvias o de carro tanques para poder suplir así sus necesidades diarias, arriesgándose así de adquirir graves enfermedades al consumir un agua que no es apta para el consumo humano y que puede contener diferentes tipos de microorganismos, lo cual es lo que la vuelve un agua insana.

Algunos de los factores que contribuyen a disminuir la calidad del agua son los sistemas que funcionan de manera intermitente, plantas de tratamiento poco eficientes, ausencia de desinfección o existencia de problemas en este proceso, redes de distribución precarias, 
conexiones domiciliarias clandestinas o mal hechas y por último, la contaminación del agua se presenta al interior de las casas, debido a la falta de higiene en el manejo de esta por parte de los usuarios.

El buen tratamiento y desinfección del agua conlleva un impacto muy significativo para la salud humana, esto debido a que la probabilidad de adquirir una infección disminuye cuando el nivel de contaminación del agua es bajo o nulo. Cuando no se presenta un adecuado tratamiento del agua, esta puede afectar en mayor medida a la población anciana y a los niños entre 0 a 5 años que son la población que cuenta con bajas defensas y por lo tanto se encuentran más propensos a adquirir enfermedades de origen hídrico y de los alimentos como frutas, verduras, pescados y mariscos crudos. Los niños de edad escolar son uno de los grupos más vulnerables frente al riesgo de adquirir enfermedades infecciosas, adicionalmente la probabilidad de contagio hacia sus familiares cercanos se incrementa (Iannacone, Benites y Chirinos, 2006).

Los métodos más comunes utilizados según Vidal (2010) como desinfectantes del agua son: ebullición solar, cloración y ozonificación. Actualmente existe un producto natural en el mercado, que es capaz de garantizar que el cuerpo de agua pueda mantenerse libre de bacterias patógenas, este producto hace referencia a la llamada Plata Coloidal, además de que La Plata Coloidal es un desinfectante natural, compuesta por nano partículas de plata, proteína de origen animal y agua bidestilada, es un bactericida, biosida, germicida y antibacterial, que elimina los microorganismos presentes en el agua, alimentos crudos, frutas verduras, legumbres y utensilios de cocina. No es toxico, tiene un efecto residual permanente, un amplio espectro bactericida, ya que elimina más de 600 clases de microorganismos patógenos, además, no tiene olor ni sabor y no es corrosivo.

Según García (2002), en su investigación realizada con estos elementos de desinfección, los resultados arrojaron que de entre estos métodos de desinfección para el agua y los alimentos, el uso de plata coloidal resultó ser el más efectivo con un porcentaje de eliminación de bacterias y microorganismos patógenos en un 100\%. Dadas las características del nuevo producto, se realizó la investigación para conocer la intención de compra del mismo y las prácticas usuales del segmento en estudio, para la desinfección de agua y alimentos.

Con todos estos antecedentes, el objetivo de este estudio fue identificar las prácticas más comunes de desinfección del agua y de alimentos (frutas y verduras) utilizadas por las amas de casa y así mismo medir la intención de compra de dicho segmento frente a un nuevo producto que cumpla esta función.

\section{Metodología}

Se realizó una investigación cuantitativa transversal simple y se definió como población objetivo las amas de casa de estrato 3, 4, 5 y 6 . Se trabajó bajo un muestreo aleatorio simple, controlando el estrato socioeconómico, con una muestra de tamaño 100 que corresponde a un nivel de confianza del $94.06 \%$, un margen de error del $3.9 \%$. La encuesta se realizó en el mes de mayo de 2015, en los diferentes condominios y barrios de la ciudad de Santiago de Cali.

\section{Resultados}

Se realizó un análisis del entorno en lo que concierne a dicho producto, con el fin de conocer las diferentes ofertas de productos similares y sustitutos que se encuentran en el mercado encontrando que como competencia directa existe en el mercado un producto llamado Bacdyn Plus, el cual cuenta con características similares a las del nuevo producto. Como productos sustitutos se encontró: Ecoflora Cares el cual es un Limpiador natural para frutas y verduras, la empresa Ecolife cuenta con un producto llamado Kilol que también hace parte del mercado de los productos desinfectantes natural a base de semillas de toronja para frutas y verduras, y la empresa Pigeon cuenta con un producto limpiador de 
accesorios de bebé, juguetes, frutas y vegetales llamado Limpiador de Biberones.

Sin embargo a comparación de la oferta de productos en dicho mercado, se ha manifestado que las amas de casa no tienen conocimiento de estos ya que los productos y métodos utilizados por dicho público objetivo con el fin de limpiar y desinfectar los alimentos son más cotidianos, los cuales hacen referencia al jabón de cocina, el vinagre, límpido, cloro y en algunos casos se mezclan estos productos para la desinfección como el jabón y el vinagre o jabón y límpido entre otros.

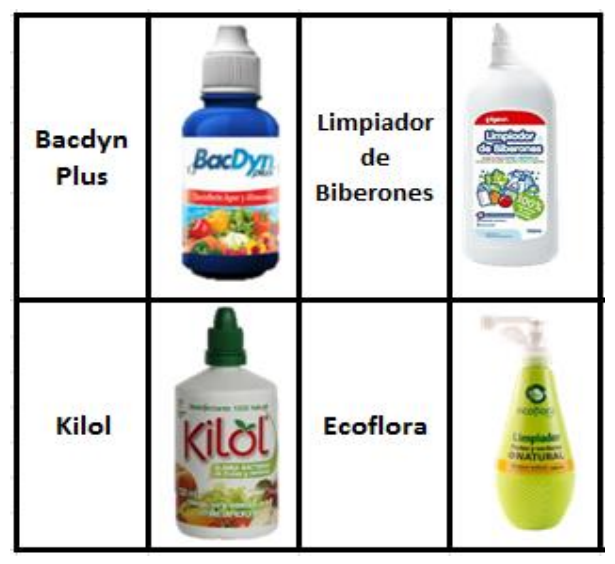

Figura 1. Productos para desinfección:

Fuente: Elaboración Propia

Las ventajas diferenciales del nuevo producto se basan en una serie de características especiales, como por ejemplo, que este producto se puede utilizar en el hogar para diversos alimentos, ya que su efecto desinfectante y eliminador de todo tipo de microorganismos patógenos actúa en el agua, en las legumbres, las frutas y verduras, además de que el producto se puede utilizar en cualquier tipo de recipiente.

\section{Desinfección del agua}

Específicamente si se habla del agua podemos observar que el $30 \%$ de las amas de casa compran agua para su consumo semanalmente, ya que consideran que el agua que sale de la llave no es segura para la preparación de los alimentos y bebidas. Al realizar el análisis se observa que el 52,85\% (37 personas) desinfectan el agua antes de consumirla, de los cuales el $67,56 \% \quad$ (25 personas) optan por hervirla como método de desinfección y el 32,43\% (12 personas) utilizan el filtro como método para purificar el agua. Y el otro 47,14\% (33 Personas) no utilizan ningún método para desinfectarla ya que consideran que consumir el agua de la llave no es causante de ningún problema. Los resultados se observan en la figura 1.

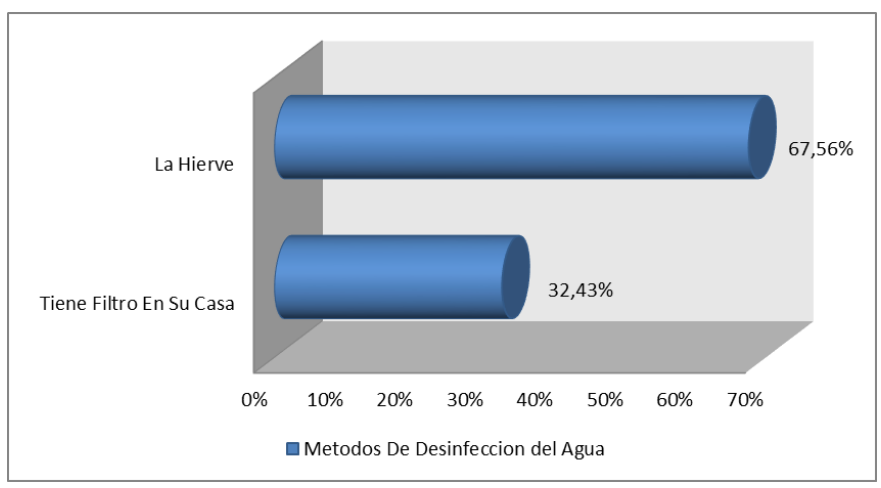

Figura 2. Métodos de desinfección del agua:

Fuente: Elaboración propia

\section{Desinfección de frutas y verduras}

Para poder empezar a hablar sobre los diferentes métodos de desinfección de las frutas y verduras, se debe de analizar la percepción de las amas de casa del porque es importante desinfectar estos alimentos y su conocimiento sobre las ventajas de utilizarlos. En la tabla 1 se observa la percepción general del segmento en estudio.

En esta tabla de liker se observa que en la afirmación numero 1 las amas de casa están total o parcialmente de acuerdo con que la mala desinfección de los alimentos causan enfermedades estomacales con un $93 \%$ de aceptación y un $2 \%$ de desacuerdo, esta afirmación y la afirmación numero 7 muestra que para las personas el no desinfectar los alimentos puede causar enfermedades pero en la afirmación numero 7 vemos que existe una diferencia ya que en esta afirmación se genera un $84 \%$ en total o parcialmente de acuerdo. Esto expone que hay personas que se contradicen y que no están muy seguro si la desinfección 
genera o no enfermedades estomacales. Seguido de la afirmación numero 2 el cual revela la importancia que ven las amas de casa en la desinfección de frutas y verduras con un $91 \%$ en total o parcialmente de acuerdo, dando la idea de que para el mercado objetivo si es importante desinfectar los alimentos. A continuación la importancia de la desinfección de frutas y verduras se puede analizar con las afirmaciones 3 y 4 el cual señala que las personas están total o parcialmente de acuerdo en un $90 \%$ que el consumo de frutas y verduras sin desinfectar puede generar un alto riesgo para la salud, ambas afirmaciones con los mismos resultados.

En la afirmación número 5 se observa que las personas acostumbran a desinfectar los alimentos, con un $86 \%$ en total o parcialmente de acuerdo y un $11 \%$ indiferente, con estos resultados se concluye que aunque para la mayoría de las personas es importante desinfectar los alimentos, al momento de hacerlo no todas tienen dicha costumbre y para algunos no les es importante si la desinfectan o no.

Para finalizar esta tabla de liker se contempla las afirmaciones 6 y 8 con un $85 \%$ y $67 \%$ en total o parcialmente de acuerdo, esto manifiesta que las personas no están del todo seguras de que las frutas y verduras vienen contaminadas desde el momento en el que son regados, y cuando llegan a los hogares.

El $98 \%$ del mercado objetivo consume verduras; de los cuales en el tema de desinfección el $55 \%$ opta por enjuagarlas con agua, un $25 \%$ la hierve, seguido de un $12, \%$ que prefiere utilizar otros métodos alternativos a la hora de desinfectar las verduras. Por otro lado en un porcentaje menor, podemos observar que en lo que concierne a la desinfección de las verduras, el $4 \%$ utiliza el cloro en estas, seguido de un $3 \%$ que las lava con otras sustancias.

El $100 \%$ de las personas consumen y desinfectan las frutas; de los cuales al momento de desinfectar podemos ver que el $75 \%$ de las personas optan por enjuagar las frutas solamente con agua, seguido de otros métodos para desinfectar con un $11 \%$ y con menores porcentajes se encuentran que las lavan con otra sustancia, utilizan cloro y las hierven con un 5\%, $6 \%$ y $3 \%$ respectivamente.

\begin{tabular}{|c|c|c|c|c|c|}
\hline $\begin{array}{l}\text { Íte } \\
\text { m }\end{array}$ & Afirmación & $\begin{array}{l}\text { Tot } \\
\text { arc } \\
\text { ent } \\
\text { Act } \\
\text { o }\end{array}$ & & $\begin{array}{l}\text { Indife } \\
\text { rente }\end{array}$ & $\begin{array}{l}\text { Total/ } \\
\text { Parcia } \\
\text { lmente } \\
\text { en } \\
\text { Desac } \\
\text { uerdo }\end{array}$ \\
\hline 1 & $\begin{array}{l}\text { Causa de } \\
\text { enfermedades } \\
\text { estomacales es } \\
\text { debido a mala } \\
\text { desinfección }\end{array}$ & $\begin{array}{l}93 \\
\%\end{array}$ & $5 \%$ & & $2 \%$ \\
\hline 2 & $\begin{array}{l}\text { Es importante la } \\
\text { desinfección de } \\
\text { frutas y verduras }\end{array}$ & $\begin{array}{l}91 \\
\%\end{array}$ & $9 \%$ & & $0 \%$ \\
\hline 3 & $\begin{array}{l}\text { Consumo de } \\
\text { ensaladas sin } \\
\text { desinfectar } \\
\text { puede generar un } \\
\text { alto riesgo para } \\
\text { la salud }\end{array}$ & $\begin{array}{l}90 \\
\%\end{array}$ & $7 \%$ & & $3 \%$ \\
\hline 4 & $\begin{array}{l}\text { Consumo de } \\
\text { frutas y verduras } \\
\text { en la calle genera } \\
\text { un alto riesgo } \\
\text { para la salud }\end{array}$ & $\begin{array}{l}90 \\
\%\end{array}$ & $7 \%$ & & $3 \%$ \\
\hline 5 & $\begin{array}{l}\text { Buena costumbre } \\
\text { en desinfección } \\
\text { de los alimentos }\end{array}$ & $\begin{array}{l}86 \\
\%\end{array}$ & $11 \%$ & & $3 \%$ \\
\hline 6 & $\begin{array}{l}\text { Las verduras que } \\
\text { se venden vienen } \\
\text { contaminadas }\end{array}$ & $\begin{array}{l}85 \\
\%\end{array}$ & $8 \%$ & & $7 \%$ \\
\hline 7 & $\begin{array}{l}\text { El consumir } \\
\text { alimentos crudos } \\
\text { bien } \\
\text { desinfectados } \\
\text { evita problema } \\
\text { estomacales }\end{array}$ & $\begin{array}{l}84 \\
\%\end{array}$ & $13 \%$ & & $3 \%$ \\
\hline 8 & $\begin{array}{l}\text { En las verduras } \\
\text { se utiliza agua } \\
\text { contaminada } \\
\text { para su riego }\end{array}$ & $\begin{array}{l}67 \\
\%\end{array}$ & $15 \%$ & & $18 \%$ \\
\hline
\end{tabular}

Fuente: Elaboración propia 
Estos datos nos dan a conocer que la mayoría de las personas solo enjuagan las frutas cuando las van a consumir, y que no encuentran otro método para la desinfección de las frutas ya que los otros datos no son relevantes para poder concluir que hay otro método importante para la desinfección de frutas.

\section{Percepción sobre el lanzamiento del nuevo producto.}

En el siguiente diagrama se observa que la percepción de las personas es positiva para el nuevo producto ya que el $80 \%$ de los encuestados piensan que un producto desinfectante natural sería útil para el hogar, seguido de un $14 \%$ de personas que le es indiferente si existe un producto de este tipo, y por último se ve un $6 \%$ de encuestados que piensas que sería un producto inútil, como se observa en el siguiente gráfico.

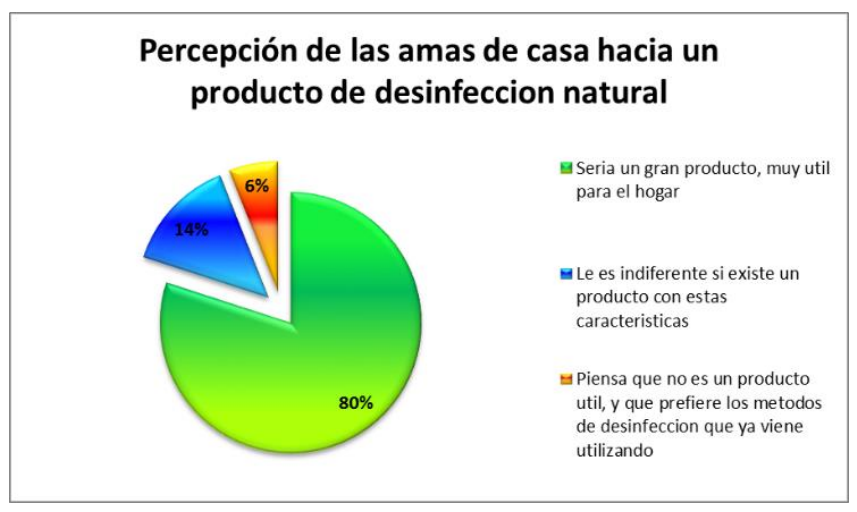

Figura 2. Intención de compra nuevo producto

Fuente: Elaboración propia

Por otra parte si se observa la actitud y la importancia que el mercado tiene hacia el nuevo producto podemos concluir que es positiva, ya que el $75,50 \%$ de los encuestados tiene una perspectiva muy buena/buena y un $71,20 \%$ dicen muy importante/importante, pero al momento de medir la intención de compra del producto se observa que esta disminuye a un $67,10 \%$. Con esto podemos concluir que aunque las personas piensen que es un producto bueno e importante, dudan en el momento en que podrían llegar a querer comprar el producto por diferentes razones como la confiabilidad o en gastar dinero en un producto que no conocen (ver tabla 2).

\section{CATEGORIA}

\begin{tabular}{|c|c|c|c|}
\hline Actitud & $\begin{array}{l}\text { Muy Buena } \\
\text { / Buena } \\
75,50 \%\end{array}$ & $\begin{array}{l}\mathrm{Ni} \quad \text { Mala } \\
\text { Ni Buena } \\
22,30 \%\end{array}$ & $\begin{array}{l}\text { Mala / } \\
\text { Muy Mala } \\
2,20 \%\end{array}$ \\
\hline $\begin{array}{l}\text { Import } \\
\text { ancia }\end{array}$ & $\begin{array}{l}\text { Muy } \\
\text { Importante / } \\
\text { Importante }\end{array}$ & Neutral & $\begin{array}{l}\text { No es } \\
\text { Important } \\
\text { e / } \\
\text { Ninguna } \\
\text { Importanc } \\
\text { ia En lo } \\
\text { Absoluto } \\
10,60 \%\end{array}$ \\
\hline $\begin{array}{l}\text { Intenci } \\
\text { ón de } \\
\text { compr } \\
\text { a }\end{array}$ & $\begin{array}{l}\text { Definitivam } \\
\text { ente Lo } \\
\text { Comprara / } \\
\text { Probableme } \\
\text { nte Lo } \\
\text { Comprara }\end{array}$ & $\begin{array}{l}\text { Tal Vez } \\
\text { Lo } \\
\text { Compre o } \\
\text { Tal Vez } \\
\text { No }\end{array}$ & $\begin{array}{l}\text { Probable } \\
\text { mente Lo } \\
\text { Comprara } \\
\text { / } \\
\text { Definitiva } \\
\text { mente No } \\
\text { Lo } \\
\text { Comprara } \\
10,70 \%\end{array}$ \\
\hline
\end{tabular}

Tabla 2. Actitud hacia el nuevo producto

Fuente: Elaboración propia

\section{Conclusiones}

En el mercado solamente existe una competencia directa del nuevo producto de desinfección natural, ya que los demás productos son especializados en necesidades distintas a las del nuevo producto.

Una de las practicas más utilizadas por las amas de casa para la desinfección del agua es la de hervirla antes de consumirla, sin embargo, este hábito no es utilizado por la mayoría de las personas, ya que para ellos el agua que proviene de la llave es potable y no es necesario aplicarle ningún método de desinfección antes de ser consumida.

Para las frutas y verduras, se concluye que el método más utilizado es el enjuague con agua 
de la llave antes de su consumo, cabe aclarar que existen otros métodos de desinfección de estas, pero ninguno es utilizado por un grupo considerable de amas de casa.

Para finalizar es importante resaltar que la percepción de las amas de casa con el nuevo producto de desinfección natural es positiva, piensan que es importante desinfectar los alimentos para así evitar enfermedades, y que un producto con estas características puede ser muy útil en los hogares; pero existe un cierto nivel de desconfianza cuando se habla de la intención de compra, ya que el producto tiene tantos beneficios, que a las personas les parece increíble que tenga tantas bondades, por lo que se les hace necesario probarlo para poder dar testimonio de sus beneficios y así generar confianza en el producto.

\section{Referencias}

Castro, D., \& Mosquera, G. (2013, 22 de Junio). "El panorama de las ETAs en Colombia", sitio web de Revista IALIMENTOS, [en línea], disponible

en: www.revistaialimentos.com.co/ediciones/edicion es-2013/edicion-32/food-safety-2/el-panoramade-las-etas-en-colombia.htm

Devera, R., Blanco, Y., \& García, L. (2006). "Parásitos intestinales en lechugas comercializadas en mercados populares $y$ supermercados de Ciudad Bolívar, Estado Bolívar, Venezuela". Revista de la Sociedad Venezolana de Microbiología, 26, p. 100-107.

Departamento Administrativo Nacional de Estadística (2008). "Encuesta de Calidad de Vida. Presentación Resultados Generales", sitio web de Departamento Administrativo Nacional de Estadística DANE, [en línea], disponible en: http://www.dane.gov.co/files/investigaciones/co ndiciones_vida/calidad_vida/Presentacion_mar1 8boletin.pdf

García, J. (2002). "Evaluación de compuestos desinfectantes en la eliminación de Vibrio cholerae y escherichia coli presentes en agua". XXVIII Congreso Interamericano de Ingeniería Sanitaria y Ambiental. Cancún, México.

Iannacone, J., Benites, M., \& Chirinos, L. (2006). "Prevalencia de infección por parásitos intestinales en escolares de primaria de Santiago de Surco, Lima, Perú". Parasitol Latinoam, 61, p. 54.62 .

Instituto Nacional de Salud. (2012). "Informe Epidemiológico Nacional 2012, Enfermedades Transmisibles, Enfermedades Transmitidas Por Alimentos ETA Cólera", sitio web de Instituto Nacional de Salud (Colombia), [en línea], disponible en: http://www.ins.gov.co/lineas-deaccion/Subdireccion-

Vigilancia/Informe\%20de\%20Evento\%20Epide miolgico/Informe\%20final\%202012/Final\%202 012\%20Enf.\%20Transmisibles\%20ETA.pdf

Rayner, M., \& Scarborough, P. (2005). "The burden of food related ill health in the UK". $J$ Epidemiol Community Health, 59, p. 1054-1057.

Solarte, Y., Peña, M., \& Madera, C. (2006). "Transmisión de protozoarios patógenos a través del agua para consumo humano". Colombia Médica, 37 (1), p. 74-82.

Vidal, S. (2010). "Evaluación de la efectividad del filtro a base de arcilla y plata coloidal en la potabilización del agua, medida por pruebas fisicoquímicas y microbiológicas". (Tesis de Pregrado) Universidad Tecnológica de Pereira. Pereira. 